\title{
Toponímias e Questões Espaço-Culturais: Identidades em Raposa - MA
}

\author{
Toponymies and Space Cultural Questions: Identities in Raposa - MA
}

Toponimias y Cuestiones Espacio-Culturales: Identidades en Raposa - MA

RESUMO: A cidade de Raposa, localizada no Maranhão, tem a sua história vinculada à pesca e à renda de bilro, protagonizado por pescadores e rendeiras, respectivamente, que migraram do Ceará, na década de 1950, para aquela que futuramente seria denominada Praia de Raposa. Este artigo tem por objetivo compreender a origem e o significado dos termos toponímicos Raposa, Praça Chico Noca e Porto do Braga, sendo estes dois últimos antigos pescadores cearenses que tiveram Raposa como novo lar. Para tal, foram desenvolvidas entrevistas semiestruturadas com moradores e com o Secretário de Cultura de Raposa, mapas temáticos e consulta bibliográfica. Identificamos que tais espaços identitários trouxeram à tona a memória individual e coletiva, sendo esse um exercício de resgate da própria história de Raposa que ainda se mantém viva, caracterizando a cultura e a identidade local, reforçando assim significações que remetem ao imaginário de Raposa.

PALAVRAS-CHAVE: Toponímia. Raposa - MA. Espaço e cultura. Identidade.

ABSTRACT: The city of Raposa, located in Maranhão State, has its history linked to fishing and bilro lace, led by the fishermen and the rendeiras, respectively, that migrated from Ceará State, in the 1950 's, to the beach that would be nominated as Raposa Beach in future. This article aims to understand the origin and the meaning of the following toponymic terms Raposa, Chico Noca Square and Braga Harbor, these last two mentioned, old fishermen from Ceará that had Raposa as a new home. For that, it was developed semi-structured interviews with residents and with the Secretary of Culture, thematic maps and bibliographical research. We identified that such identity spaces brought to light the individual and collective memory, being an exercise that rescue the own history of Raposa that is still alive, characterizing the culture and the local identity, reinforcing like this, meanings that refer to the imaginary of Raposa.

KEYWORDS: Toponymy. Raposa-MA. Space and culture. Identity.

RESUMEN: La ciudad de Raposa, ubicada en Maranhão, tiene su historia vinculada a la pesca y a la producción de bilro. Protagonizada por pescadores y costureras que emigraron desde Ceará en la década de 1950, hacia la que en un futuro sería llamada de Playa de Raposa. Este artículo como fin comprender el origen y el significado de los términos toponímicos Raposa, Porto do Braga y Praça Chico Noca, siendo, los dos últimos, ex pescadores de Ceará que adoptaron a Raposa como su

\footnotetext{
${ }^{1}$ Mestre em Geografia pela Universidade Estadual do Maranhão. E-mail: alexnunes_18@hotmail.com.
} 
nuevo hogar. Con este fin, se desarrollaron entrevistas semiestructuradas con el vecindario y con el Secretario de Cultura de Raposa, mapas temáticos y consultas bibliográficas. Identificamos que tales espacios de identidad trajeron memorias individuales y colectivas, siendo este un ejercicio para rescatar la historia de Raposa que sigue viva, caracterizando la cultura y identidad local, reforzando así los significados que se refieren al imaginario de Raposa.

PALABRAS-CLAVE: Toponimia. Raposa - MA. Espacio y cultura. Identidad.

\section{INTRODUÇÃO}

O município de Raposa, em conjunto com os municípios de São Luís, São José de Ribamar e Paço do Lumiar, compõe a llha do Maranhão. Emancipada, em 1994, de Paço do Lumiar, Raposa é conhecido, entre os moradores da llha do Maranhão, por suas peculiaridades locais: a pesca, o artesanato, a renda de bilro e o turismo para a llha de Curupu, feito por meio de barcos, denominados pelos pescadores locais como "biana". Nessa porção, se encontra a Praia de Carimã, frequentada por banhistas e praticantes de esportes náuticos. De acordo com dados do Instituto Brasileiro de Geografia e Estatística, Raposa, no ano de 2019, possuía 30.761 habitantes (IBGE, 2019).

De acordo com Costa e Seabra (2015), além de levantamentos de campo, tais lembranças conferidas à Raposa são atribuídas à chegada dos primeiros pescadores oriundos do Ceará, dada a seca severa que atingiu boa parte do Nordeste durante a década de 1950. Parte dos migrantes cearenses chegou à então Praia de Raposa, trazendo consigo, posteriormente, seus familiares - pais, irmãos e esposas, conhecidas como as mulheres rendeiras de Raposa.

Dentre os pescadores que chegaram em Raposa - Chico Noca e o Braga - ambos possuem homenagem toponímica na cidade. São lembrados pelos agentes espaciais entrevistados - moradores e um representante da Prefeitura, o Secretário de Cultura. Apesar de seus nomes não estarem impressos fisicamente na praça e no porto do município, respectivamente, é evocado, na memória dos entrevistados, o exercício da lembrança daquilo que lhes foi dito a respeito da história dos agentes pesquisados.

Os depoimentos obtidos em campo, entre março de 2018 e agosto de 2019, somaramse aos espaços estudados, revelando assim as vivências e o dia a dia de uma comunidade com singularidades e aspectos em comum, que refletem um importante significativo da identidade raposense. Tais espaços possuem uma conotação simbólico-cultural que emana, entre os entrevistados, a memória de onde vivem, ou seja, onde a vida acontece diariamente.

Espaços esses aqui compreendidos como geossímbolos, pois trazem à tona, a partir das narrativas reveladas pela memória, a importância do uso dos termos topônimos locais, 
emanando assim o senso de identidade e pertencimento à Raposa, valorando o simbólico, nesses espaços do vivido e do percebido.

Nesse sentido, este artigo tem por objetivo compreender a percepção dos moradores de Raposa no que tange as toponímias Praça Chico Noca e o Porto do Braga, além da origem do termo Raposa. Para compreendermos a visão dos entrevistados acerca de tais toponímias, foram feitas entrevistas semiestruturadas, com auxílio de bibliografia que tratam de questões relacionadas à cidade de Raposa.

O desenvolvimento da pesquisa contou com entrevistas, registros fotográficos, elaboração de mapas e croqui de localização, além das bases teóricas, que concernem aos conceitos sobre toponímia e identidade, permitindo assim caracterizar e demonstrar o elo entre os raposenses com a cidade e com os espaços toponímicos em questão.

Em relação ao suporte bibliográfico, nos baseamos nos conceitos de toponímia, oriundos de literaturas nacionais e estrangeiras. Na Geografia, as abordagens sobre toponímia, identidade e geossímbolos foram obtidas através dos estudos de Claval (2010), Corrêa (2003, 2007), Haesbaert (2013), Le Bossé (2004), Bonnemaison (2012), dentre outros.

No sentido de explorar o surgimento da cidade, a chegada dos primeiros pescadores e a consolidação de Raposa como cidade, foram consultadas as pesquisas de Azevedo, Vieira e Melo (1980), Costa e Seabra (2015), Reis (2007) e Rodrigues (1998), os quais trazem dados empíricos que vêm a somar com os dados obtidos em campo para esta pesquisa.

Para fazermos análises dos significados atribuídos pelos entrevistados a respeito das toponímias de Raposa, utilizamos o método fenomenológico, tendo como foco os agentes espaciais, a partir da descrição dos objetos em análise. Desse modo, a inserção no campo empírico em tela nos permitiu conhecer o cotidiano dos agentes espaciais entrevistados, através da observação, bem como das entrevistas semiestruturadas, permitindo aos entrevistados acrescentarem informações que considerassem relevantes.

Desse modo, compreendemos que a utilização de entrevistas vai além do contato direto entre pesquisador-entrevistado para a obtenção de respostas cabíveis à pesquisa. $\mathrm{A}$ realização das entrevistas permite ao pesquisador adentrar no mundo particular e social do agente espacial em questão, na sua história com o coletivo, nos seus rituais cotidianos, revelando assim práticas que ultrapassam o individual para abranger o grupo o qual esse agente tenha ligação direta de convivência em seus mais variados modos.

Nesse sentido, em relação às entrevistas, utilizamos 0 modelo do tipo semiestruturado, em que há um roteiro previamente elaborado, porém, dando liberdade para que os entrevistados acrescentem ou sigam caminhos que venham a contribuir com as 
inquietações da pesquisa, com o intuito de conhecer mais a respeito da visão e da experiência dos agentes espaciais com as toponímias de Raposa em questão.

Nesse ínterim, construímos questões universais com os moradores de Raposa, na região central, tais como: você é de Raposa? Seus pais são cearenses? Qual seu entendimento sobre a toponímia Raposa? Algum familiar ou alguém próximo contribuiu para esse seu entendimento? Você possui conhecimento de outros espaços que remetem à identidade da cidade?

A partir das respostas universais, tivemos o conhecimento das toponímias supracitadas - a Praça Chico Noca e o Porto do Braga - sendo então construídas questões particulares sobre tais espaços de identidade com moradores que ali estavam presentes, tais como: você sabe mencionar quem foi Chico Noca? Você sabe mencionar quem foi o Braga? Qual a importância desse termo toponímico? Qual a importância em se nomear espaços de Raposa com o nome de antigos moradores (fundadores)?

Tais questionamentos nos levaram também a instigar sobre o início da construção da Praça Chico Noca e do Porto do Braga, sendo tais fatos consultados através das entrevistas e/ou de bibliografia disponível.

Percebemos o quão importante foram as narrativas para as descrições históricas que envolvem os tópicos do estudo em questão, sendo um poderoso recurso utilizado pela História Oral. Para Delgado (2006), não há somente o privilégio de fatos passados, mas também o momento presente quando os depoimentos são reproduzidos, havendo uma conexão entre a dinâmica do indivíduo com o coletivo, revelando tempos, espaços, fatos e conflitos dos objetos em análise.

Os agentes espaciais entrevistados - os moradores de Raposa - tiveram seus nomes preservados, sendo identificados ao longo do trabalho, conforme ilustrado no quadro 1, abaixo, além do Secretário de Cultura de Raposa, identificado como Sr. "R". As entrevistas com tais agentes foram construídas no período que corresponde aos meses de maio de 2018 e agosto de 2019.

Quadro 1 - Relação das entrevistas

\begin{tabular}{|l|l|}
\hline Sr. "R" & Secretário de Cultura de Raposa. \\
\hline Entrevistado 1 & Morador de Raposa, pescador, presente na Feira dos Pescadores. \\
\hline Entrevistado 2 & Morador de Raposa, pescador, presente na Orla de Raposa. \\
\hline Entrevistado 3 & Morador de Raposa, presente no Porto do Braga. \\
\hline Entrevistada 4 & $\begin{array}{l}\text { Moradora de Raposa, proprietária de uma loja de renda de bilro e parenta do } \\
\text { Chico Noca. }\end{array}$ \\
\hline Entrevistado 5 & Morador de Raposa, presente na Praça Chico Noca. \\
\hline Entrevistado 6 & Morador de Raposa, presente no Porto do Braga. \\
\hline Entrevistada 7 & $\begin{array}{l}\text { Moradora de Raposa, funcionária de um boteco localizado em frente ao Porto } \\
\text { do Braga. }\end{array}$ \\
\hline
\end{tabular}

Fonte: o próprio autor (2019). 
As reflexões mostram que a toponímia vai muito além da atribuição de nomes: é um conjunto de significados impressos que revelam a história e a geografia de uma comunidade, um município ou um país, revelando a origem e os aspectos culturais de dado bairro ou município, dentre outros, reforçando assim o sentimento de pertencer a um lugar ao lugar no qual o agente espacial se insere no mundo.

\title{
DISCUSSÃO E RESULTADOS DA PESQUISA
}

A origem de Raposa - MA é datada dos anos de 1950, época em que chegaram os primeiros pescadores oriundos do estado do Ceará, fugindo de intempéries climáticas que atingiam boa parte da região nordeste à época, como menciona Costa e Seabra (2015, p. 63-64):

Em 1958, os estados do Ceará, Paraíba e Rio Grande do Norte foram atingidos por uma das mais violentas secas já ocorridas no Nordeste Brasileiro [...]. Ao final de 1958, o total de pessoas atingidas chegava a dois milhões de habitantes, o que levou cerca de duzentas mil pessoas, já sem alternativas, a migrarem para várias outras regiões brasileiras.

Reis (2007, p. 9) menciona a chegada dos primeiros cearenses em Raposa, dentre eles, Zé Martins e Antônio Pucal:

\begin{abstract}
Em 1949, quando os primeiros pescadores se estabeleceram na praia da Raposa, podia-se contar, a princípio, com um rancho de pescadores. O Sr. Antônio e Sr. José Martins resolveram aventurar a vida no Maranhão. Chegando a São José de Ribamar, entraram em contato com o Sr. José Linhares, que os convidou para trabalhar em currais. Algumas pessoas das proximidades já pescavam, como José Cantor, que já havia feito um pequeno barraco para tratar peixes.
\end{abstract}

De acordo com Azevedo, Vieira e Melo (1980), quando chegaram à então Praia de Raposa, com toda a riqueza que a natureza lhes oferecia, voltaram ao Ceará e chamaram outros familiares para migrarem para Raposa, dentre eles, José Maria Castelo e Chico Noca. Um dos primeiros pescadores a trazer a família do Ceará para Raposa foi Chico Noca, na década de 1950. Reis (2007, p. 10) menciona:

[...] a primeira casa construída nesta Praia, foi a de propriedade do Sr. Tirite, o qual foi quem hospedou Chico Noca e toda sua família na sua chegada à Raposa. No início da década de 50 , a população raposense habitava em umas 10 residências, com uma média de 60 moradores. Já em 1980, a população era mais de 5.000 habitantes com mais de 100 unidades domiciliares. 
Com base nos dados fornecidos por Azevedo, Vieira e Melo (1980) e Rodrigues (1998), os cearenses presentes em Raposa, à época em que foram feitas as suas pesquisas, eram oriundos de Aracati, Acaraú, Camocim, São Gonçalo do Amarante, Pentecoste, Trairi e Paracuru.

É importante destacar que naquela época, a partir de estudos empreendidos pelo IBGE, Raposa ainda não possuía status de município, sendo uma vila de pescadores de Ribamar, no qual a pesca era uma das mais significativas atividades econômicas. Não por acaso, era "[...] praticada em grande escala por mais de oitocentos pescadores profissionais pertencentes à Colônia Z-3" (IBGE, 1959, p. 300).

Em 1959, Paço do Lumiar se emancipa de São José de Ribamar, conforme aponta o IBGE (1982). Devido à Lei Estadual no 1890, datada de 7 de dezembro de 1959, Paço do Lumiar é mais um município da llha do Maranhão, sendo a então vila de pescadores de Raposa pertencente ao município supracitado.

O anseio para que o povoado de Raposa se tornasse um município, segundo Rodrigues (1998), ocorreu no Legislativo, tendo início no dia 24 de agosto de 1989. O Projeto de Lei no 6132, conforme prossegue a autora, foi aprovado na Assembleia Legislativa do Maranhão e sancionado pelo então governador, José de Ribamar Fiquene, em 10 de novembro de 1994. Atualmente, a llha do Maranhão é composta pelos municípios de São Luís, São José de Ribamar, Paço do Lumiar e Raposa, conforme demonstrado na figura 1.

Figura 1 - Mapa de Localização de Raposa na Ilha do Maranhão

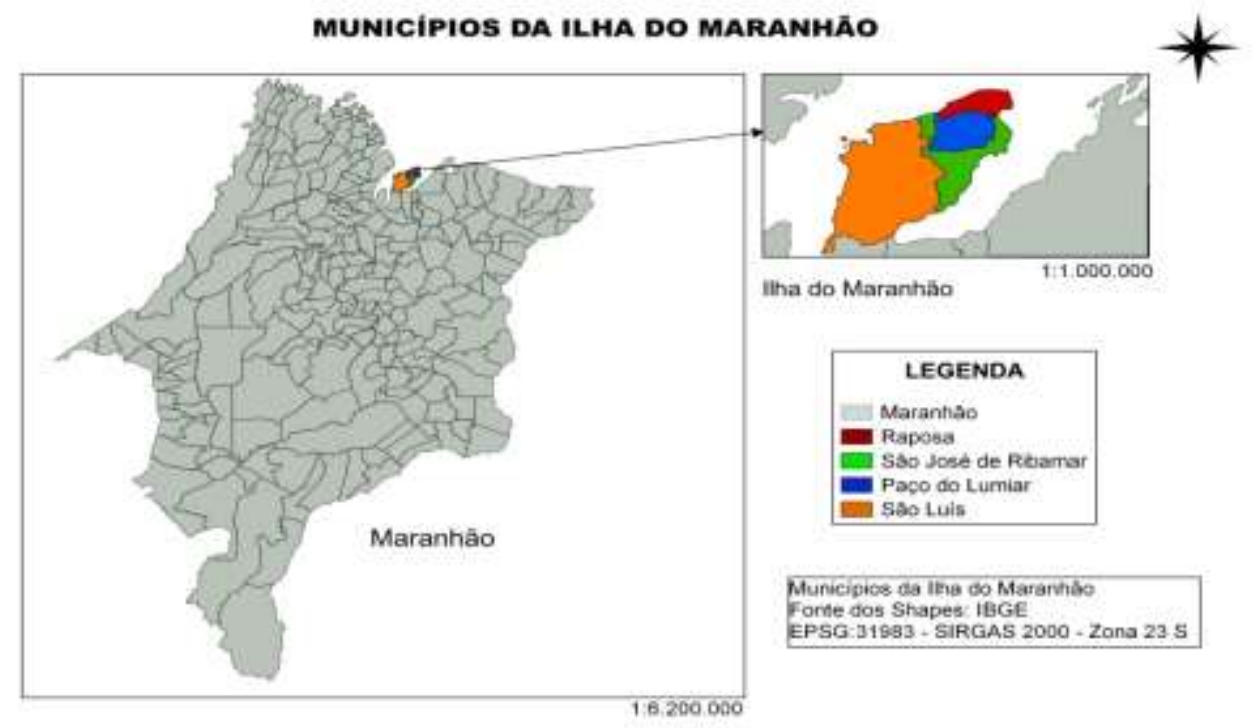

Organização: o próprio autor (2020). 
Após um breve levantamento a respeito da história de Raposa, serão tratados a seguir questões pertinentes ao significado do termo toponímia, do termo Raposa e dos termos que fazem menção aos antigos pescadores de Raposa - Chico Noca e Braga.

A toponímia, conteúdo utilizado e trabalhado nas mais variadas ciências, incluindo a Geografia, tem por objetivo compreender a origem e a questão política dos nomes atribuídos aos lugares. Serve também, de acordo com Claval (2010), para a orientação, pois a partir do conhecimento do nome de um ponto de referência, o homem consegue se orientar e se localizar no lugar em questão. Corrêa (2003, p. 176) define a toponímia como: "[...] uma relevante marca cultural e expressa uma efetiva apropriação do espaço por um dado grupo cultural. É ainda um poderoso elemento identitário. A toponímia, em realidade, articula linguagem, política territorial e identidade" (CORRÊA, 2003, p. 176).

Para Claval (2010), a toponímia serve para a descrição, além de revelar a identidade do mundo e do lugar em que os grupos espaciais estão inseridos. Tais pontos escondem significações das quais foram atribuídas tal nome, seja para uma praça, uma rua, um lago, um rio etc., sendo uma maneira de materializar, no espaço, referências e identidades de uma comunidade.

A toponímia abrange o contexto histórico, social e cultural, sendo a origem repleta de significados, em dado período do tempo vivenciado por determinados agentes espaciais. Nesse sentido, Vuolteenaho e Berg (2009, p. 8, tradução nossa) mencionam que "[...] o termo nomear é geralmente usado para abranger todos os tipos de expressões linguísticas que designam entidades ou ocorrências no mundo fenomenal".

Para Azaryahu (2009), quando se nomeiam ruas das cidades, há uma ligação com atos comemorativos do passado que remetem à identidade e ao poder, além de "[...] prover aos usuários da cidade com orientação" (2009, p. 53-54, tradução nossa). Seguindo com o raciocínio do autor, a nomeação de ruas remete-se à identidade (local, regional e nacional); é também um ato simbólico, "representar o passado" (2009, p. 55, tradução nossa); e também se remete a estruturas de poder e autoridade.

Ainda segundo o autor, "[...] a maioria dos nomes de ruas comemorativas perpetua na paisagem urbana a memória de figuras históricas e eventos dignos de homenagem pública pelas autoridades sob responsabilidade da nomeação das ruas" (AZARYAHU, 2009, p. 56, tradução nossa).

Nesse sentido, percebemos que 0 ato de nomear logradouros públicos vincula-se, muitas vezes, com a identidade local, podendo ser uma praça, um porto, uma rua ou um edifício, dentre outros. Os espaços aqui estudados são carregados de significações, sendo compreendidos como os geossímbolos de Raposa. Para Bonnemaison (2012, p. 292), o geossímbolo: "Pode ser definido como um lugar, um itinerário, uma extensão que, por 
razões religiosas, políticas ou culturais, aos olhos de certas pessoas e grupos étnicos assume uma dimensão simbólica que os fortalece em sua identidade".

Sendo assim, buscamos compreender e instigar reflexões sobre os pontos toponímicos aqui abordados: Raposa (nome do município); Praça Chico Noca (Centro de Raposa) e Porto do Braga (localizado no leste de Raposa), cujas localizações são demonstradas na figura 2.

Figura 2 - Croqui de localização dos pontos toponímicos em estudo

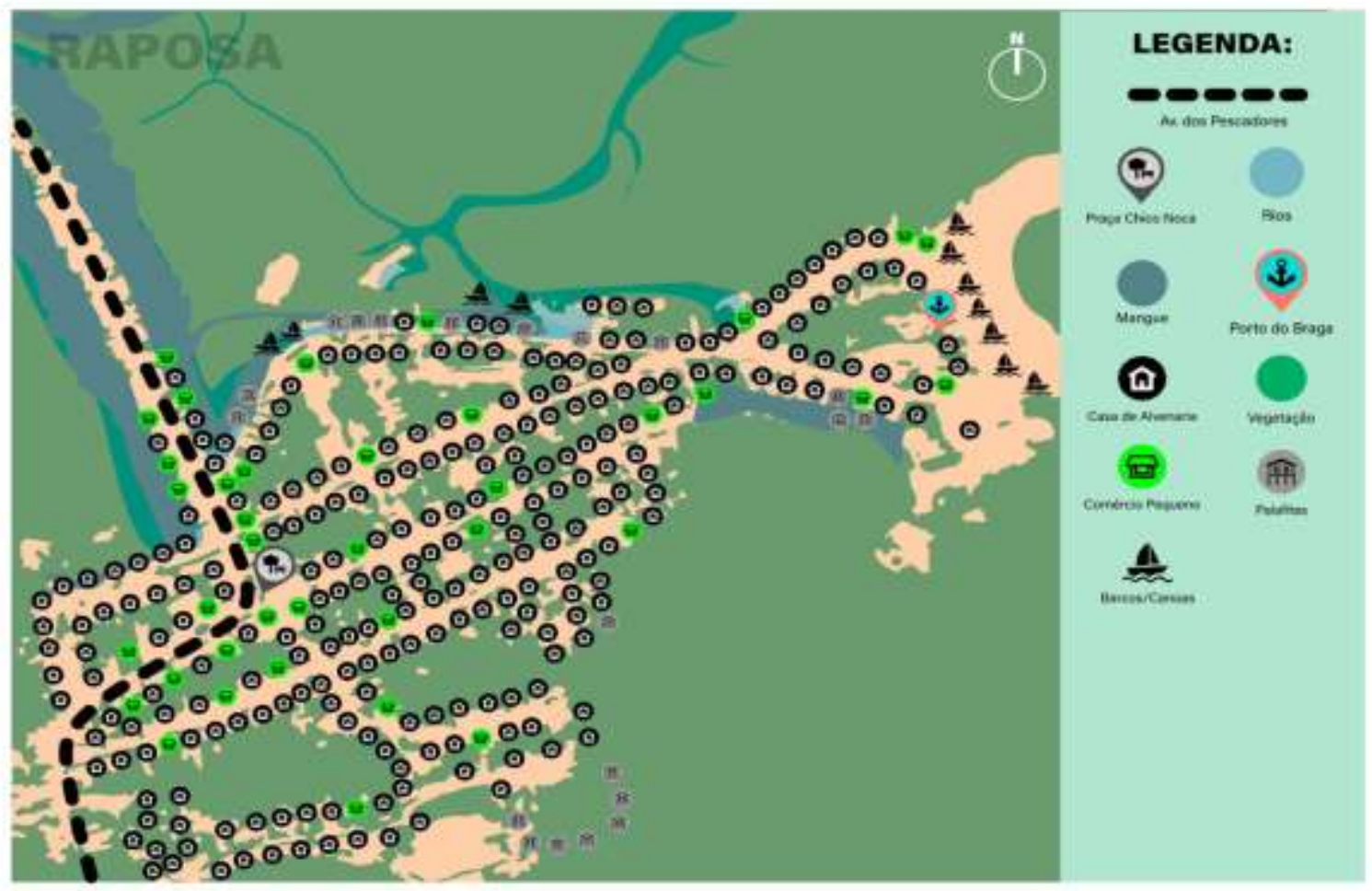

Fonte: organizado pelo próprio autor e digitalizado por Hewald (2019).

Nas proximidades da Praça de Chico Noca, localizada no centro de Raposa, na recém renomeada Avenida dos Pescadores (antiga Avenida Principal), há um intenso e vibrante comércio, como lojas de móveis, pequenos supermercados, lanchonetes, padaria, bares, restaurantes e sorveterias, dentre outros.

Além do comércio, há casas ao estilo de alvenaria e palafitas, ocupando áreas de manguezal, revelando uma problemática ambiental local, em que percebemos o descarte irregular de lixo e esgoto em áreas que deveriam ser de proteção ambiental.

Silva (2011, p. 75-76) destaca que a pesca está entre as principais atividades do(a)s que chefiam as famílias no Centro de Raposa, representando $36,67 \%$ dos entrevistados, “[...] seguido por outros serviços (26,67\%) - esse item congrega pedreiros, carpinteiros, encanadores, zeladores, vigia, diaristas, rendeiras, artesãos, dentre outros; em menor número estão os empregados domésticos". 
"Com relação aos demais membros da família, a principal ocupação é de estudante, com $56,39 \%$ no centro [...]. Os servidores públicos correspondem ao menor grupo com 2,13\%" (SILVA, 2011, p. 76-77). Ainda de acordo com o autor supracitado, em relação às donas de casa, "[...] um grande número de mulheres adultas exerce apenas a função de genitora e gestora do lar" (SILVA, 2011, p. 77).

Tal como Silva (2011) citou a respeito da grande presença de pescadores no centro de Raposa, também destacamos as rendeiras, que em muitos casos são as esposas dos pescadores. As rendeiras estão presentes na Avenida dos Pescadores, no trecho conhecido como Corredor das Rendas, em suas próprias casas de alvenaria ou palafita, transformadas em pequenas fábricas de confecção e venda de renda de bilro, mantendo ativa as tradições de décadas, ao atrair os turistas através das cores e das histórias narradas pelas mulheres rendeiras de Raposa.

Já em relação ao Porto do Braga, o espaço também é bastante dinâmico, principalmente de 7:00 da manhã às 18:00. Ali, há a presença de turistas, principalmente aos fins de semana e feriados, bem como uma intensa circulação de pescadores, que retornam ou partem para uma nova pescaria, tendo como pontos de concentração os coretos do referido porto, onde estão as redes de pesca e os barcos ali ancorados, banhados pelo igarapé que os levam para as praias mais próximas, como a de Carimã, na Ilha de Curupu, em Raposa.

Assim como na Avenida dos Pescadores, o Porto do Braga também possui um comércio com a presença de bares, restaurantes e lojas de artigo para pesca. Constatamos que em frente ao porto há um conjunto de lojas em sua maioria fechadas e poucas funcionando como restaurantes ou bares.

De acordo com o Entrevistado 1, houve ali na década de 1990 um projeto de mercado dos pescadores; porém, a ideia não foi aceita entre os próprios pescadores, pois não há a mesma dinâmica como na atual Feira dos Pescadores de Raposa, próximo ao Corredor das Rendas: “[...] não é como aqui (Feira dos Pescadores). Isso aqui é 24 horas. Aqui tudo é vendido aqui, até sardinha. Lá não tem esse movimento e a maré fica seca, os ônibus param aqui".

Após uma breve caracterização dos referidos espaços, questionamos a origem do termo Raposa, remetendo à própria história da cidade. Costa e Seabra (2015, p. 65) mencionam que há três versões para sua origem. A primeira surgiu a partir de um depoimento dado pelo pescador Valdemar, conhecido como Grandão:

Os pescadores faziam "salga" da pescaria na praia, improvisando abrigos em cajueiros onde pernoitavam. No entanto, a presença constante das raposas (atraídas pela quantidade considerável de pássaros na localidade) que avançavam e comiam o pescado começou a preocupá-los, pois os 
mesmos não podiam sair para pescar deixando os peixes na salga, que as raposas os roubavam. Um dia, apareceu uma raposa morta na beira da praia e, como os nativos acreditavam que onde morre uma raposa, as outras não voltam mais, resolveram criar naquele local o Rancho da Raposa.

A segunda versão é oriunda "[...] de uma pesquisa geoeconômica do município de Paço do Lumiar (1969), na qual constatou-se que a denominação Raposa seria resultado da alusão a um dos primeiros moradores do lugar: Maia Raposo" (COSTA; SEABRA, 2015, p. $65)$.

A terceira versão dada pelas autoras, com base em Azevedo, Vieira e Melo (1980), diz respeito ao encontro, por dois homens, de uma raposa morta na Praia de Carimã, que posteriormente se tornou um ponto de encontro, tendo por referência o local onde encontraram a raposa morta, sendo denominado como Raposa. Contudo, nesta terceira versão, a partir dos depoimentos adquiridos em campo, percebemos novos direcionamentos e algumas divergências, no sentido de que a raposa foi morta e/ou encontrada morta na praia.

Durante as visitas de campo, questionamos os agentes espaciais sobre o conhecimento da toponímia Raposa. Na Orla de Raposa, nas proximidades do Centro de Apoio ao Turista, paramos para conversar com o Entrevistado 2. De acordo com ele, o nome do município faz referência ao animal raposa, em vasta abundância na época em que os cearenses chegaram. Ele ainda menciona: "Rapaz, dizem os antigo que aqui tinha muita raposa [...]. Quando chegaram aqui, encontraram muito elas, aí botaram o nome Raposa aqui, que tinha bastante".

Em outro ponto da cidade, no Porto do Braga, conversamos com o Entrevistado 3, o qual mencionou que o local em que a raposa foi morta pelos pescadores transformou-se em um ponto de encontro e de referência entre eles. A raposa morta se tornou um símbolo imaterial, que serviria para nomear a recente vila de pescadores cearenses. Assim, o Entrevistado 3 menciona:

[...] quando chegaram os primeiros moradores daqui, era pescador, era uma vila de pescador, e eles foram numa bela pescaria, né? E lá ficou nas dunas de Carimã, e lá eles mataram uma raposa, né? Como não tinha referência na época, ele disse assim: rapaz, a gente vai amanhã que horas pescar? Rapaz, a gente vai sair às 4 horas da madrugada, a gente se encontra lá na Raposa, que era aonde a raposa tava morta, entendeu? E quando [...] fundaram o lugar, e aí botaram o nome de Raposa, entendeu? Aí ficou, todo tempo, com essa história, aí pronto. Batizaram como Raposa, aí ficou, até que eu acho bacana esse nome, Raposa.

Já a versão mencionada pela Entrevistada 4, proprietária de uma loja de renda de bilro em Raposa, se deu a partir da visão do seu parente, o próprio Chico Noca. Segundo a 
Entrevistada 4, a toponímia Raposa ocorreu por conta de uma raposa morta que se encontrava na praia, vista pelos pescadores. Daí a origem do nome. Ela ainda afirma que:

Isso aqui, [...] foi assim, [...] surgiu como um ponto de referência, porque nesse dia eles acharam [...] aonde eles estavam tinha uma raposa morta, e aí os pescadores estavam lá e eles queriam se reencontrar [...]. Vai ser lá no local, vai ser naquele local da raposa, lá onde tá a raposa morta. E ficou Raposa, proveniente do animal mesmo, e aqui também tinha muita raposa, tudo extinto, tudo acabou.

As entrevistas ajudaram a revelar que, apesar de haver múltiplas versões a respeito dos aspectos relacionados ao animal raposa - como foi encontrada pelos pescadores - o que há em comum entre os resultados obtidos é que a raposa se tornou uma referência, dando nome à comunidade dos pescadores que, futuramente, iria ser nomeada como município. Nesse sentido, afirma Halbwachs (1990, p. 25): "[...] tudo se passa como se confrontássemos vários depoimentos. É porque concordam no essencial, apesar de algumas divergências, que podemos reconstruir um conjunto de lembranças de modo a reconhecê-lo".

Tais memórias aqui descritas, a respeito de Raposa, revelaram a importância e o significado que a cidade tem para com seus habitantes. São memórias que remetem ao social - dos que ali vivem e fazem a vida acontecer. Esse aspecto é destacado por Halbwachs (1990), ao defender que tem como primazia as memórias coletivas, nas quais há uma relação entre o indivíduo e o coletivo - esse último privilegiado - no qual ele se encontra inserido, permitindo a construção de significados comuns que remetem à memória do grupo social.

Como percebemos até aqui, Raposa, no início, era uma pequena vila de pescadores situada em uma praia até então distante do centro de São Luís. Tais pescadores vieram do Ceará, fugindo das intempéries climáticas que abatiam aquele estado.

Nesse sentido, o processo de deslocamento dos cearenses ocorreu, em alguns casos, com a ajuda dos primeiros pescadores que chegaram em Raposa. Costa e Seabra (2015, p. 64) citam que "[...] grande parte dos migrantes de Acaraú foi transportada para a Raposa na 'biana' de seu Chico Noca”. Feitosa e Trovão (2006) consideram a biana como um tipo de embarcação similar a uma canoa, possuindo apetrechos como vela e/ou motor, diferenciando-a também em seu tamanho, sendo maior que a canoa.

Chico Noca é bastante conhecido na cidade, o que the rendeu uma homenagem toponímica: uma praça. De acordo com o Secretário de Cultura do município, Sr. "R", a praça foi inaugurada há 35 anos (1984), estando localizada na recém renomeada Avenida dos Pescadores, outrora conhecida como Avenida Principal. 
De acordo com Reis (2007), a Praça Chico Noca (figura 3) foi a primeira do município de Raposa. No entanto, antes de se transformar em uma praça e ser nomeada como Chico Noca (figura 4), o espaço passou por mudanças ao longo dos anos, como será descrito a seguir.

Figura 3 - Praça Chico Noca, Raposa - MA

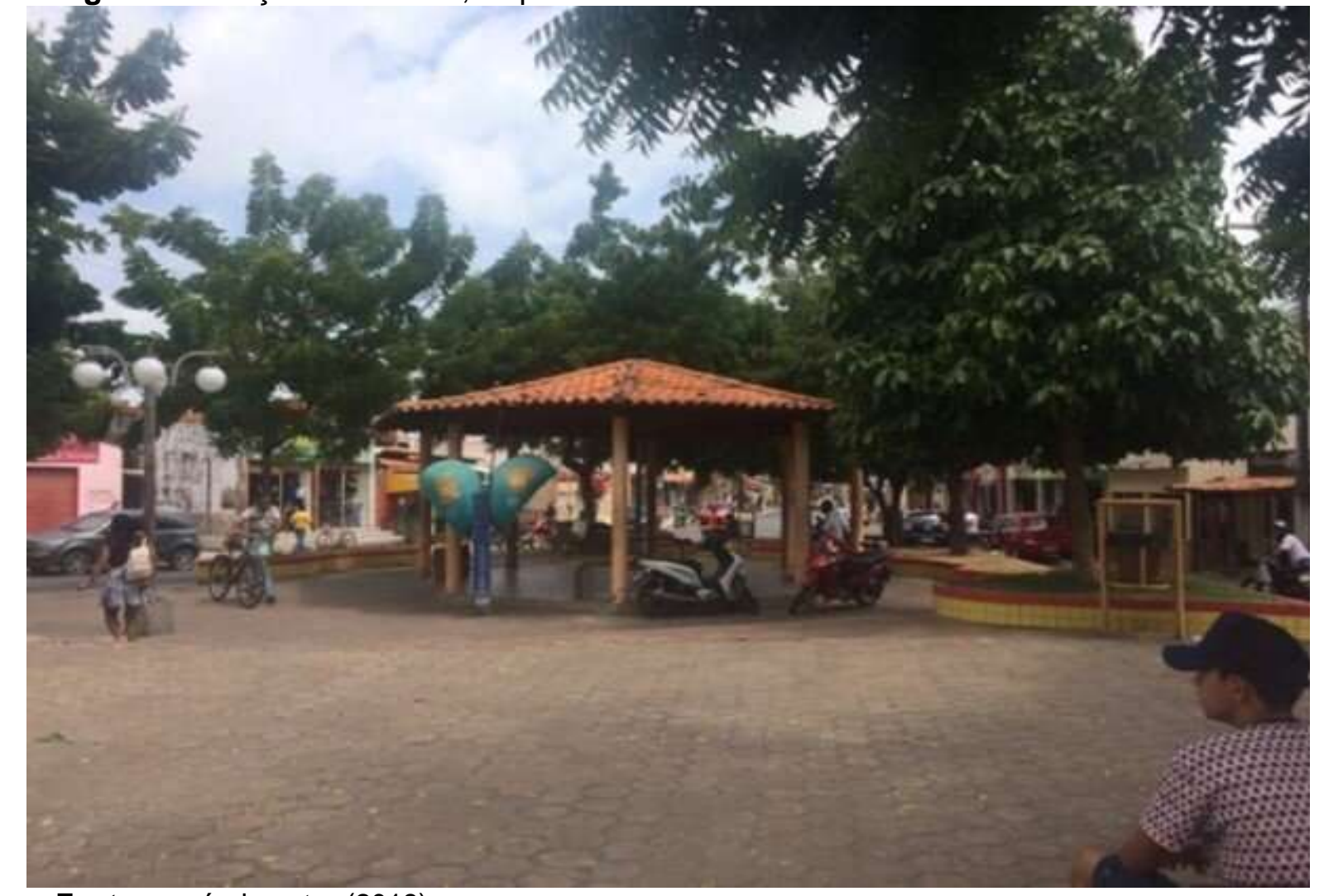

Fonte: o próprio autor (2018).

Figura 4 - Chico Noca

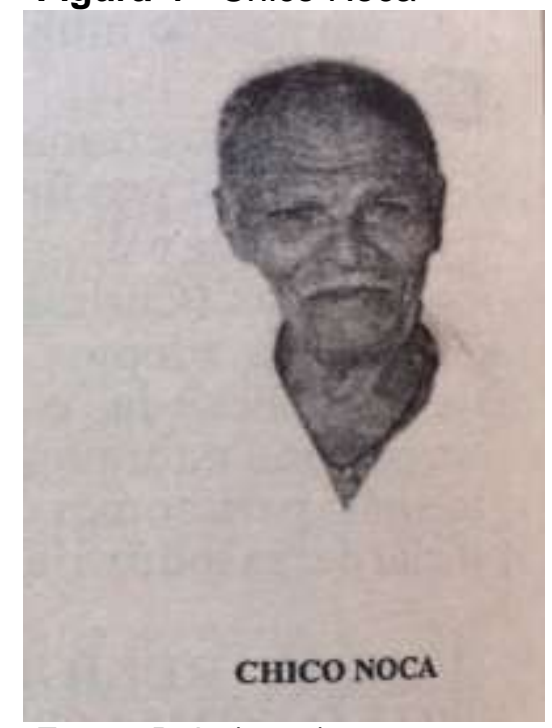

Fonte: Reis (2007). 
Tais mudanças, como relata Reis (2007), ocorreram a partir da instalação da estrada com camada de piçarra em Raposa, sobrando um lote que as crianças utilizavam para brincar. Nesse espaço, foi instalado um bar, construído por Antônio Maurício dos Santos - o Carapeba. Após certo tempo, a praça foi demolida pela prefeitura de Paço do Lumiar e ocupada por uma escola pertencente ao referido município. Anos depois, o qual o autor não especifica, a escola foi demolida, dando lugar a uma nova praça, a Praça Chico Noca que, para o Secretário de Cultura de Raposa, Sr. "R", foi inaugurada entre as gestões dos exprefeitos de Paço do Lumiar: Joaquim Aroso e Peixoto.

Hoje em dia, a Praça Chico Noca é bastante frequentada por estudantes das escolas próximas, sentados em grupo. Além dos estudantes, idosos e senhoras. A praça também serve como ponto de mototaxistas, agrupando dezenas deles naquele espaço.

Para entender mais a respeito da vontade popular em torno da nomeação da Praça como Chico Noca, já que ela é conhecida como tal, realizamos entrevistas com os agentes espaciais, dentre esses, a Entrevistada 4, mencionada anteriormente. A Entrevistada 4 é neta do referido homenageado. Ela foi questionada a respeito da concretização formal desse termo na praça; além da presença desses e de outros elementos materiais e imateriais, como homenagem a outros personagens de Raposa. Assim a Entrevistada 4 relata:

Não, não tem nada disso... até a praça, que é a praça Chico Noca, não tem nada dele, que a gente queria até, eu tava até pensando em reivindicar isso pras autoridades aqui pra ver se fazem pelo menos isso, já que o nome dele. A praça é o nome dele, em homenagem a ele, devia fazer ao menos uma escultura, alguma coisa, fazendo um nome, só o nome pra representar, mas não tem, infelizmente, não tem nada [...]. Tem o Porto do Braga, que também é o nome de um outro pescador antigo, que fica lá [...] é muito bonito lá, é muito lindo, que é uma homenagem também ao senhor chamado Braga. O seu Braga, que foi um pescador muito antigo daqui, que já faleceu também, mas não tem nada dele, nem nome tem, nenhuma coisa.

A teoria de Corrêa (2007, p. 11) se reflete na fala da Entrevistada 4, para o qual, "[...] a toponímia constitui uma forma simbólica que identifica um logradouro público, bairro, cidade, país ou forma da natureza, atribuindo-Ihes um significado que pode valorizar ou estigmatizar o próprio objeto". Nesse sentido, percebemos que, para a Entrevistada 4, a praça em si ainda não representa aquilo que Chico Noca trouxe de contribuição para o que é Raposa hoje, e que são necessários esforços conjuntos para que a homenagem de fato se (i)materialize naquele espaço.

Durante as visitas de observação na Praça Chico Noca, conversamos com o Entrevistado 5, morador do município, presente na referida praça. O questionamos qual era 
seu conhecimento a respeito de Chico Noca e sobre a homenagem toponímica feita ao antigo pescador da cidade.

Com certeza! Alguém que descobriu a Raposa, que foi o Chico Noca. Foi o primeiro a chegar na llha aqui, nesse pedaço. E então vale a pena levar o nome dele da Praça Chico Noca, né? Ele residia aqui, e dos outros que chegaram junto com ele, tem o Cau. Tem uns e outro que botaram o nome ni rua. É bom. Uma coisa dessa fica bom, porque fica conhecido, porque a geração que vem, ela vai sabendo quem foi o Chico Noca, pra conhecer a história da cidade. O Chico Noca que foi o primeiro que chegou aqui na Raposa, fulano de tal, os outro que eu não sei te dizer o nome que não tá na cabeça. E aí, as geração que tá vindo que aqui é tudo uma família. Quando ele veio, ele trouxe toda a turma do Ceará, do Acaraú, no Ceará e foi transformando e foi crescendo a família, a maior parte é tudo família. Então é importante a Raposa ter o nome das praças, dos colégio; que tem colégio aqui que tem nome de professor que já foi, que já morreu, que é o José França e uma e outras coisas que tem o nome do povo da Raposa, que ajudou a fundar a Raposa.

O Entrevistado 5 revela a importância em nomear logradouros do município com o nome dos antigos pescadores que ali chegaram, pois assim as futuras gerações terão conhecimento da importância dessas pessoas na construção da identidade raposense.

Então, aqui quase tudo na Raposa é botado o nome dos fundadores dos morador antigo da Raposa. E isso é bom porque a geração que vem, vai conhecendo quem foi. "Rapaz, quem foi o Mané Diano, de que família ele foi? Quem foi o Chico Noca?". E aí vai levando, e as pessoa vai, os mais novinho vai levando.

Tomando como base a narrativa do Entrevistado 5, percebemos em seu relato a toponímia como um modo de exaltação à memória e à identidade. Na Geografia Cultural, a memória e a identidade, como representação, estão correlacionadas com o tempo e o espaço. O tempo está relacionado com a época em que se desenrolou a historicidade dos fatos, tanto no passado, como no presente e no futuro; e o espaço, onde a ação se desenvolveu, simbolizado através de monumentos e materializando, em tais espaços, as memórias individuais e também coletivas. Sobre essa temática, afirma Johnson (2004, p. 317 , tradução nossa):

A transmissão e tradução de significado através do tempo e espaço é, ambos, central ao ritual da vida cotidiana aos monumentos excepcionais de lembrança associados com nascimento, morte, e outros eventos chave nas histórias pessoal e coletiva. A memória como re-coleção, relembrança, e rerepresentação é crucial no mapeamento de momentos históricos significantes e na articulação da identidade pessoal.

Há, desse modo, a necessidade de compreendermos a memória individual, "[...] a qual é praticada dentro de cadeias neurais do indivíduo" (JONES; GARDE-HANSEN, 2012, p. 6, 
tradução nossa), e a memória coletiva, "[...] a qual está amarrada entre pessoas, objetos, textos, mídia e através do tempo e espaço" (JONES; GARDE-HANSEN, 2012, p. 6, tradução nossa). Ao entrevistarmos os agentes espaciais de Raposa, percebemos a menção indireta às questões relacionadas ao espaço habitado e ocupado, ao lugar enquanto reprodutor de antigas práticas e mantenedor de suas práticas territoriais-identitárias.

Dessa maneira, para Jones e Garde-Hansen (2012, p. 11, tradução nossa), a relação entre a Geografia e o estudo da memória (e suas práticas), atualmente, está mais relacionada à questão das memórias individuais, pois a partir dessa o homem cria uma relação com o espaço vivido, oriunda de suas experiências, refletindo na construção de sua identidade, do vir a ser, nas vivências, em que a "[...] memória (de um tipo ou de outro) é então um aspecto geográfico fundamental do vir a ser, intimamente entrelaçada com o espaço, afeição, emoção, imaginação e identidade".

A relação entre a Geografia e a identidade, para Le Bossé (2004, p. 158), ocorre através do interesse do geógrafo "[...] pela identidade dos lugares e dos papéis que eles desempenham na formação de consciências individuais e coletivas". Le Bossé (2004, p. 163) traz um direcionamento a respeito do conceito de identidade.

A identidade é uma construção social e histórica do "próprio" [do soi, do self] e do "outro", entidades que, longe de serem congelados em uma permanência "essencial", estão constante e reciprocamente engajadas e negociadas em relações de poder, de troca ou de confrontação mais ou menos disputáveis e disputadas que variam no tempo e no espaço.

Dentre uma das questões abordadas com o Entrevistado 2, o questionamos a respeito da importância da representatividade toponímica, em se nomear o município e outros pontos da Raposa com o gentílico de antigos e primeiros moradores que ali chegaram.

Eu achava que sim [...]. Porque hoje a gente tem que, primeiro lugar: tem que se dar o valor ao lugar, porque quando se dá o valor ao lugar tem [...], pelo menos que botar um nome nos primeiros habitantes que veio pra cá com a rua. Que nem essa praça tem, né? E outras coisas mais... pôr o nome de alguém. [...] São Luís todo tem o nome de alguém que veio em primeiro lugar logo lá pra São Luís. Principalmente, no centro. E porque que aqui não pode ter? Eu acho que poderia ter.

Compreendemos que os depoimentos citados mencionam o significado das identidades territoriais, carregados de significações capazes de emanar a identidade local entre os agentes espaciais, e também de pertencimento, através desses territórios simbólicos, nos quais "[...] as identidades se situam frente a ou a num espaço simbólico, social/ historicamente produzido" (HAESBAERT, 2013, p. 238). 
O Entrevistado 6, presente no Porto do Braga, relata que os locais que levam os nomes dos primeiros moradores da Raposa ajudam a reforçar a identidade da cidade e que também servem como pontos de referência para os turistas e para os que trabalham com o turismo: "[...] e é até um ponto de referência para o turismo que a gente trabalha nessa área, já manda a localização do Porto do Braga, entendeu? "

O Porto do Braga, ilustrado na figura 5, possui bares, lanchonetes e serviços, como lojas voltadas para atender os pescadores, além de uma passarela adjunta ao igarapé. É um dos pontos visitados por turistas que passeiam pela cidade.

Figura 5 - Porto do Braga

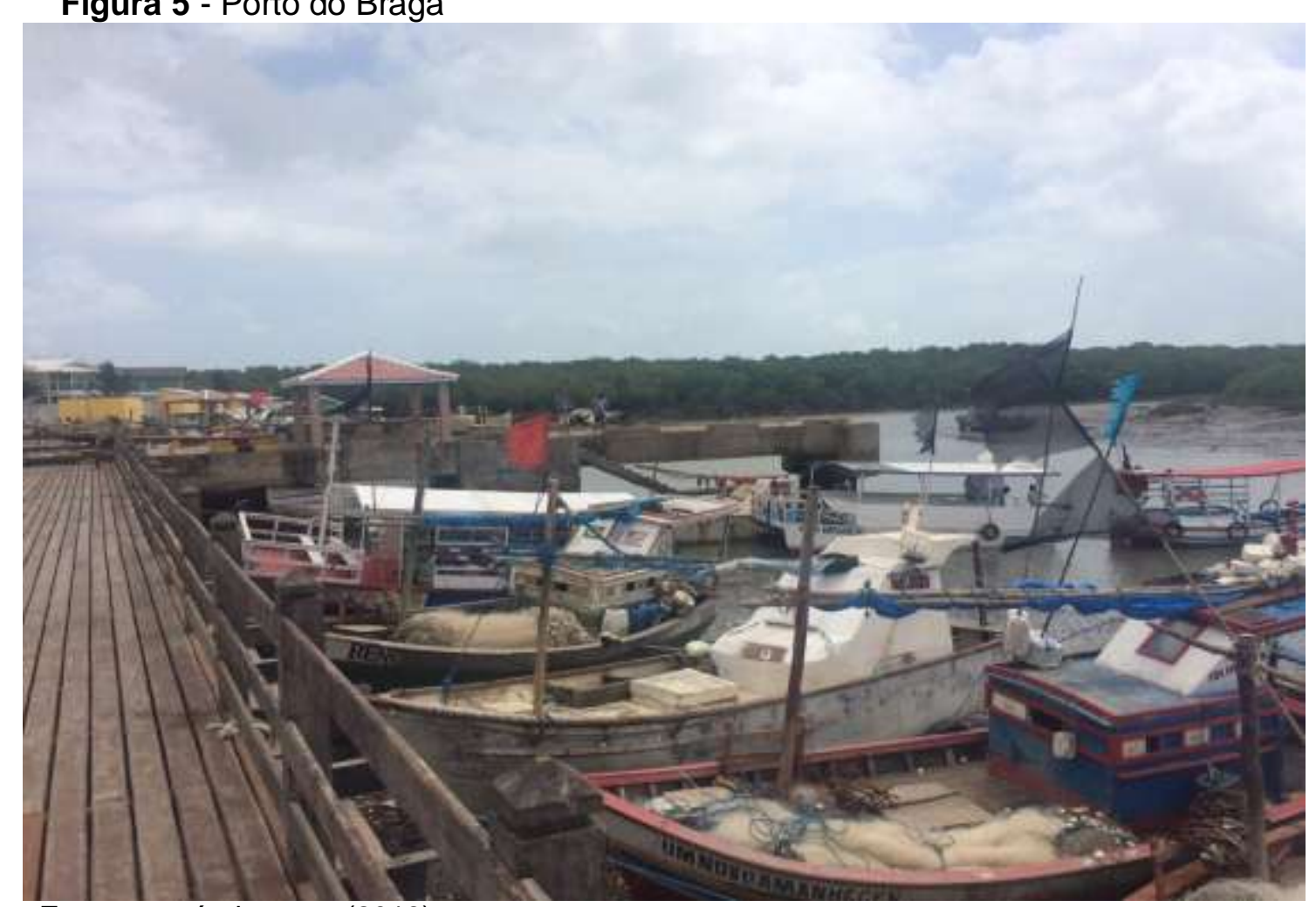

Fonte: o próprio autor (2018).

De acordo com a entrevista realizada com a Entrevistada 7, funcionária de um boteco localizado em frente ao referido porto, o Braga foi um dos primeiros pescadores, vindo do Ceará, que chegaram em Raposa. Para ela, “[...] ele também é um dos antigos personagens daqui morador daqui, foi um dos primeiros que veio. Ele faleceu [...], foi o mais recente, foi o que faleceu, um ano e meio, dois anos, é o Seu Braga [...]".

No Porto do Braga, percebemos um fluxo considerável de pescadores, que se concentram nos coretos ao longo do píer do porto. Muitos estão em duplas ou em grupo, conversando ou fazendo ajustes nas redes de pesca. É um espaço mais tranquilo, quando comparado a outros espaços, como a Feira dos Pescadores, onde há um movimento intenso de pescadores e compradores ao longo de todo o dia. 
No porto também há uma considerável movimentação de caminhões que transportam o pescado para outras regiões da llha do Maranhão, além de muitos barcos ancorados, em que pescadores fazem ajustes para uma próxima pescaria.

O Entrevistado 6 mencionou que o Porto do Braga é bem antigo, em torno de 35 anos. Contudo, de acordo com o Secretário de Cultura, Sr. "R", o porto foi inaugurado com "[...] mais ou menos 15 anos" (2004) e reformado em 2017 - os coretos e o píer do Porto". Para o secretário, o Braga é "o dono das terras - o Sr. Raimundo Braga, familiares que até hoje moram lá. Ele foi um dos pioneiros do município [...]. Uma parte (das terras), ele doou e a outra, ele foi negociando".

Para Azaryahu (2009, p. 54, tradução nossa), “[...] quando usado para fins comemorativos, os nomes de ruas e a versão do passado apresentam, à esfera pública, a composição simbólica da identidade local e nacional”. Ao se nomear ruas, cidades e outros pontos dessas localidades, por trás desse ato há também outros elementos imateriais relacionados à emoção, ao vínculo, ao poder e à sua detenção.

Dessa maneira, percebemos que há grande valoração por partes dos entrevistados quando mencionam, através das toponímias dos pescadores cearenses, os fatos e a história que configuram a vila de pescadores de Raposa, sendo esses pontos uma forma de (i)materializar a imagem de Raposa, a partir daqueles que ali chegaram e ajudaram a construir uma nova terra de oportunidades para os emigrados cearenses.

\section{CONSIDERAÇÕES FINAIS}

A toponímia não é somente um nome inscrito em uma placa que serve de orientação ou de identificação de uma rua ou praça, diferenciando-a das demais. A toponímia é uma forma de linguagem espacial, que descreve as memórias de antigos agentes espaciais; memórias de fatos que marcaram uma comunidade.

É um processo de trabalho da imaginação, do reconectar-se ao passado, de vínculos que ali foram estabelecidos individualmente ou coletivamente, permitindo ao homem o poder do conhecimento do seu mundo, diferenciando-se de outros espaços, no qual as singularidades, a partir do viés cultural, ganham forma e imagem, através dos discursos que ajudam a criar a paisagem cultural e expressam o sentimento de pertencimento e de vínculo, que liga ao homem ao seu território.

As toponímias abordadas neste estudo, tendo como análise uma porção da cidade de Raposa-MA, fazem referência, em sua maioria, aos primeiros pescadores cearenses que chegaram àquela que seria denominada Praia de Raposa, na década de 1950. As narrativas demonstraram que, através do exercício de manifestação da memória dos entrevistados, pelos motivos que os quais pensam ser importante tal fato toponímico, esse é um modo de 
manter parte da história de Raposa, daqueles que fugiram da seca e trouxeram consigo os familiares.

Sendo assim, a toponímia é um poderoso recurso que, além de estimular a memória identitária, liga os homens com seus territórios. Nesse território, ocorre a (re)produção de práticas antigas e cotidianas, mostrando-se, também, como um elemento simbólico para que as novas gerações conheçam e se apropriem do imaginário cultural que ainda se faz presente em Raposa.

\section{REFERÊNCIAS}

AZARYAHU, Maoz. Naming the Past: The Significance of Commemorative Street Names. In: BERG, Lawrence D.; VUOLTEENAHO, Jani. Critical Toponymies: The Contested Politics of Place Naming. Surrey: Ashgate Publishing Limited. 2009. p. 53-70.

AZEVEDO, Ramiro Corrêa; VIEIRA, Maria do Socorro Monteiro; MELO, Elenice Bezerra. Raposa: uma visão antropolinguistica. São Luís: SIOGE, 1980.

BONNEMAISON, Jöel. Viagem em torno do território. In: ROSENDAHL, Zeny; CORRÊA, Roberto Lobato. Geografia Cultural: uma antologia. Rio de Janeiro: EdUERJ, 2012. p. 279304.

CLAVAL, Paul. Terra dos Homens: a geografia. São Paulo: Contexto, 2010.

CORRÊA, Roberto Lobato. A Geografia Cultural e o Urbano. In: CORRÊA, Roberto Lobato; ROSENDAHL, Zeny. Introdução à geografia cultural. Rio de Janeiro: Bertrand Brasil, 2003. p. 167-186.

CORRÊA, Roberto Lobato. Formas simbólicas e espaço: algumas considerações. Revista Geographia, Ano IX, no 17, p. 7 - 18, 2007. Disponível em:

http://www.geographia.uff.br/index.php/geographia/article/view/212/204. Acesso em: 24 jun. 2018.

COSTA, Raquel Pires; SEABRA, Maria Cândida Trindade Costa de. As palavras sob um viés cultural: o léxico dos pescadores da Raposa, Maranhão. São Luís: UEMA, 2015.

DELGADO, Lucília de Almeida Neves. História oral - memória, tempo, identidades. Belo Horizonte: Autêntica, 2006.

FEITOSA, Antonio Cordeiro; TROVÃO, José Ribamar. Atlas Escolar do Maranhão: Espaço Geo-Histórico e Cultural. João Pessoa: Grafset, 2006.

HAESBAERT, Rogério. Identidades Territoriais. In: ROSENDAHL, Zeny; CORRÊA, Roberto Lobato. Geografia Cultural: uma antologia. Volume II. Rio de Janeiro: EdUERJ., 2013. p. 233-244.

HALBWACHS, Maurice. A memória coletiva. São Paulo: Vértice, 1990.

IBGE. Enciclopédia dos Municípios Brasileiros. XV Volume. Rio de Janeiro, 1959.

IBGE. Coleção de Monografias Municipais: Paço do Lumiar, Maranhão. Nova Série, no 38, 1982.

IBGE. Raposa - MA. 2019. Disponível em: https://cidades.ibge.gov.br/brasil/ma/raposa/panorama. Acesso em: 10 abr. 2020.

JOHNSON, Nuala C. Public Memory. In: DUNCAN, James S.; JOHNSON, Nuala C.; SCHEIN, Richard H. A Companion to Cultural Geography. Malden, MA: Blackwell Publishing, 2004. p. 316-328. 
JONES, Owain; GARDE-HANSEN, Joanne. Geography and Memory: Explorations in Identity, Place and Becoming. New York: Palgrave Macmillan, 2012.

LE BOSSÉ, Mathias. As questões de identidade em geografia cultural - algumas concepções contemporâneas. In: CORRÊA, Roberto Lobato; ROSENDAHL, Zeny. Paisagens, Texto e Identidade. Rio de Janeiro: EdUERJ, 2004. p. 157-179.

REIS, José Ribamar Sousa dos. Cidade de Raposa: encanto das águas. Revista A Biana. Edição 01. Fevereiro de 2007. Ano 1. Raposa, 2007.

RODRIGUES, Roseane Silva Erre. A criação do município de Raposa: Uma análise da origem legal. Monografia (Graduação em História Licenciatura) - Centro de Estudos Básicos. Universidade Federal do Maranhão. São Luís, 1998.

SILVA, Ney. Cidade de Raposa: Análise geográfica do espaço socioambiental. São Luís: NS Editor, 2011.

VUOLTEENAHO, Jani; BERG, Lawrence D. Towards Critical Toponymies. In: BERG, Lawrence D.; VUOLTEENAHO, Jani. Critical Toponymies: The Contested Politics of Place Naming. Surrey: Ashgate Publishing Limited. 2009. p. 1-18.

Recebido: março de 2020. Aceito: agosto de 2020. 